\title{
PENGARUH STORE IMAGE PERCEPTION, DAN STORE BRAND PRICE IMAGE TERHADAP STORE BRAND PURCHASE INTENTION DENGAN PERCEIVED RISK SEBAGAI VARIABEL MEDIASI
}

\author{
Didy Surjana \\ Program Studi Magister Manajemen Universitas Tarumanagara \\ didyysurjana@gmail.com
}

\begin{abstract}
The store brand is one of strategy that retailers used for competing in the market which is getting tighter every single day. Based on previous research, there were several factor that influence purchase intention.this study aims to determine the effect of, strore image, perceived risk, and price image on purchase intention at modern market in Jakarta. The researh method used in this study is PLS-SEM, and the data collected by structured quistionaires. Sample that used in this study is 204 respondents. And as the result, the direct effect of store image is the only variabel that wasn't had a significant influence on purchase intention.
\end{abstract}

\begin{abstract}
Abstrak : Store brand merupakan bentuk strategi yang digunakan dalam bersaing bagi peritel dalam pasar yang makin hari persaingannya makin ketat. Berdasarkan penelitian terdahulu, terdapat beberapa faktor yang mempengaruhi minat beli yaitu store image, perceived risk, dan price image. Penelitian ini bertujuan untuk mengetahui pengaruh store image, perceived risk, dan price image terhadap purchase intention pada salah satu pasar swalayan di Jakarta. Metode penelitian yang digunakan dalam penelitian ini partial least square-structural equation model (PLS-SEM). Teknik yang digunakan untuk pengumpulan data adalah survei dengan menggunakan kuisioner terstruktur. Populasi dan sampel dalam penelitian ini adalah pengunjung ataupun pembeli salah satu pasar swalayan di Jakarta dengan hasil sebanyak 204 responden yang dapat digunakan dalam penelitian ini. Hasil dari penelitian menunjukkan bahwa hanya store image yang tidak berpengaruh signifikan terhadap purchase intention.
\end{abstract}

Keywords: store brand, image, price, ritail, purchase intention

\section{PENDAHULUAN}

Di kota besar seperti di Jakarta, keberadaan pasar swalayan sudah tersebar dimanamana. Ritel-ritel tersebut ada yang dibangun di atas lokasi tersendiri ataupun terpadu dengan pusat perbelanjaan. Jumlah penduduk Indonesia yang besar menyebabkan sektor FMCG (Fast Moving Consumer Goods) menjadi daya tarik bagi investor untuk membuka ritel-ritel baru. Terutama setelah dibukanya pintu masuk bagi para peritel asing sebagaimana Keputusan Presiden No. 118/2000, sejak itu ritel asing mulai marak masuk ke Indonesia (marketing.co.id, 2013).

Store brands atau yang dikenal juga sebagai private label adalah merek, produk yang dimiliki, dan dijual oleh pengecer sendiri dengan mengusung nama pengecer dan hanya diperuntukkan bagi pengecer tersebut (Selvaraj, 2015). Untuk para pengecer store brands menjadi suatu sarana yang dapat diandalkan untuk meningkatkan penjualan secara cepat dan dengan biaya yang rendah. Pelanggan juga rela untuk membeli produk peritel (PLMA, 2009). Meskipun kehadirannya mengundang banyak perdebatan, private label berkembang pesat. Sejumlah ritel modern berlomba-lomba meluncurkan produk dengan merek sendiri (private label). Niat atau keinginan membeli nantinya akan mempengaruhi pilihan pelanggan dalam melakukan pembelian. Niat beli pelanggan yang tinggi pada suatu produk store brand akan memberikan suatu keunggulan kompetitif bagi perusahaan karena pada akhirnya akan 
menimbulkan loyalitas. (Forbes, 2011). Selain itu penelitian ini juga ingin membandingkan hasil anatara penelitian yang dilakukan oleh peneliti sebelumnya yakni Diallo (2012) dan juga penelitian Sibarani dan Hananto (2015) untuk mengetahui dalam meneliti ritel moderen, mana yang lebih berpengaruh signifikan antara variabel price image, perceived risk, atau store image.

\section{TINJAUAN PUSTAKA \\ Store brand}

Store brands atau yang dikenal juga sebagai private label adalah merek, produk yang dimiliki, dan dijual oleh pengecer sendiri dengan mengusung nama pengecer dan hanya diperuntukkan bagi pengecer tersebut (Selvaraj, 2015). Lebih lanjut, store brand juga dapat diartikan sebagai merek yang dikembangkan sendiri atau langsung oleh peritel (Bao, Yeqing, \& Shibin, 2010).

\section{Store image perception}

Store image adalah gambaran keseluruhan yang mana lebih dari hanya sekedar kesimpulan berdasarkan bagian tertentu suatu toko, dimana setiap bagian berhubungan satu dengan yang lainnya dalam pikiran konsumen (Utami, 2010). Berikutnya, menurut Suryana (2013) Citra toko merupakan persepsi konsumen terhadap suatu toko dibandingkan dengan toko lainnya. Masing-masing konsumen mempunyai persepsi yang berbeda antara toko yang satu dengan yang lainnya tergantung dari citra setiap toko. Citra toko dapat juga diartikan sebagai persepsi konsumen dari sebuah toko dan membandingkannya dengan toko kompetitor (Bloemer \& Shroder, 2002).

\section{Perceived risk toward store brand}

Perceived risk adalah rasa ketidakpastian yang dimiliki konsumen ketika membeli sesuatu barang/produk, persepsi mengenai risiko sering terjadi khususnya ketika konsumen membeli barang yang mahal (Lake, 2016). Perceived risk mengacu kepada kepercayaan subjektif dari infividu mengenai potensi dari konsekuensi negatif dari keputusannya dalam memilih produk yang digunakannya (Bauer, 1960). persepsi publik tentang risiko dibangun secara rasional dan berfokus pada probabilitas, biaya dan manfaat terkait (Knox, 2000).

\section{Store brand price image}

Store brand price-image diartikan sebagai representasi global dari tingkat harga relatif suatu produk store brand untuk pengecer tertentu (Diallo, 2012). Price image juga adalah sebuah variabel multidimensi yang terdiri dari beberapa dimensi perseptual tentang konsekuensi yang diterima peritel dari kebijakannya dalam menentukan harga (Zielke, 2010). Berdasarkan definisi-definisi diatas, maka disimpulkan pada penelitian ini,price image merupakan evaluasi dari satu set harga relatif terhadap beberapa standar, seperti tingkat harga pengecer yang bersaing (Hamilton, 2008).

\section{Purchase intention}

minat beli dapat diartikan sebagai suatu sikap senang terhadap suatu obyek yang membuat individu berusaha untuk mendapatkan obyek tersebut dengan cara membayarnya dengan uang/pengorbanan (Schiffman \& Kanuk, 2010). Lebih lanjut, minat beli adalah bagian dari tindakan pengambilan keputusan yang mana meneliti alasan untuk membeli suatu merek oleh konsumen (Shah, et al., 2012). Dari definisi-definisi sebelumnya, maka dapat disimpulkan minat beli adalah perilaku konsumen yang muncul sebagai respons terhadap objek yang menunjukkan keinginan pelanggan untuk melakukan pembelian (Kotler \& Keller, 2009). 


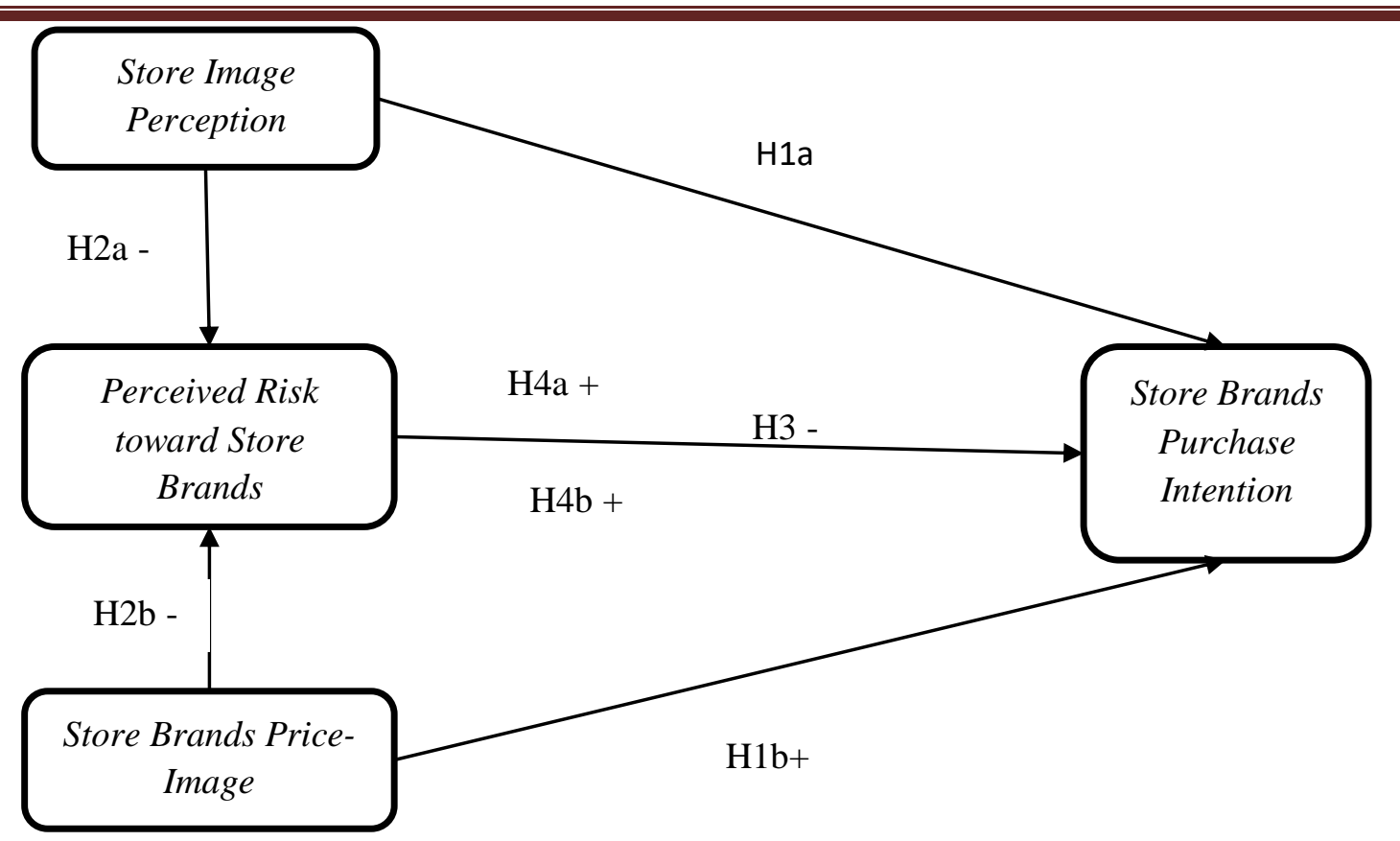

Gambar 1

Model Penelitian

*Notes: $\mathrm{H} 4 \mathrm{a}$ and $\mathrm{H} 4 \mathrm{~b}$ are represented as indirect effects.

\section{Pengembangan hipotesis}

\section{Kaitan Antara Store Image dan Price Image Dengan Purchase Intention}

Menurut Paul, dkk (2011) image akan berpengaruh pada citra dan niat beli pada private label brands. Hasil dari penelitian menunjukan ketika menguji secara bersama-sama store image berpengaruh langsung pada purcahse intention private label brands, tapi tidak pada private label image. Diallo, Chandon, Cliquet, dan Philippe (2013) menyatakan store image perception berpengaruh signifikan dan positif terhadap store brand purchase intention baik itu pengaruh secara langsung ataupun tidak langsung. Dan price image juga berpengaruh bahwa faktor citra merupakan determinan yang penting dari store brand choice. Store image perception menjadi elemen kunci dalam store brand purchase behavior. Disimpulkan bahwa merek toko tidak begitu terkait dengan harga yang diberikan lebih penting bagi peritel untuk meningkatkan persepsi mengenai kualitas. Berdasarkan uraian diatas maka hipotesis pertama dalam penelitian ini adalah sebagai berikut:

$\mathrm{H}_{1}$ : a) store image perception; b) store brand price-image berpengaruh positif terhadap store brand purchase intention pada salah satu pasar swalayan di Jakarta.

\section{Kaitan Antara Store Image dan Price Image Dengan Perceived Risk}

Selanjutnya, pada penelitian yang dilakukan Sibarani dan Hananto (2015) store image perception, dan store brand price image berpengaruh negatif dan signifikan terhadap variabel perceived risk. Namun price image tidak menunjukkan hasil yang signifikan terhada perceived risk. Dapat dikatakan dalam penelitian tersebut semakin tinggi store image, perceived risk terhadap produk store brand akan cenderung berkurang. Sedangkan untuk variabel price image yang tidak diterima kemungkinan disebabkan terjadi karena jenis produk yang ditawarkan oleh ritel yang diteliti tersebut adalah produk personal, dimana masingmasing konsumen memiliki pertimbangan sendiri dalam memilih produk, murah ataupun mahal tidak berpengaruh terhadap minat beli konsumen (Sibarani \& Hananto, 2015). Atas penelitian-penelitian terdahulu maka hipotesis kedua pada penelitian ini adalah sebagai berikut:

$\mathrm{H}_{2}$ : a) store image perception; b) store brand price-image berpengaruh negatif terhadap perceived risk toward store brands pada salah satu pasar swalayan di Jakarta. 


\section{Kaitan Antara Perceived Risk Dengan Purchase Intention}

Persepsi terhadap risiko berpengaruh tinggi pada minat beli konsumen untuk produk private label/store brand (Dursun, Ebru, \& Sezen, 2012). Jadi ketika konsumen menganggap produk store brand yang tidak familiar memiliki risiko yang tinggi maka konsumen akan menganggap produk tersebut sebagai produk yang berisiko untuk dibeli dan lebih memilih produk national brand yang sudah lama dikenal (Sibarani \& Hananto, 2015). Berdasarkan penelitian yang dilakukan Diallo (2012), didapati hasil yang menunjukkan perceived risk berpengaruh negatif dan signifikan terhadap purchase intention yang mana menunjukkan menurunnya persepsi akan risiko dari membeli produk store brand akan semakin meningkatkan minat beli konsumen.hasil berbeda didapat dari penelitian yang dilakukan oleh Sibarani, dan Hananto (2015) yang mana menunjukkan hasil yang bertolak belakang yang mana berarti semakin tinggi persepsi risiko terahdap store brand tidak berpengaruh negatif terhadap niat beli konsumen. Berdasarkan uraian tersebut maka hipotesis ketiga dalam penelitian ini adalah:

$\mathrm{H}_{3}$ : Perceived risk toward store brands berpengaruh negatif terhadap store brand purchase intention pada salah satu pasar swalayan di Jakarta.

\section{Kaitan Antara Store Image, dan Price Image Terhadap Purchase Intention dengan Perceived Risk Sebagai Variabel Mediasi}

Diallo, Chandon, Cliquet, dan Philippe (2013) menyatakan store image perception berpengaruh signifikan dan positif terhadap store brand purchase intention baik itu pengaruh secara langsung ataupun tidak langsung. Dan price image juga berpengaruh bahwa faktor citra merupakan determinan yang penting dari store brand choice. Store image perception menjadi elemen kunci dalam store brand purchase behavior. Disimpulkan bahwa merek toko tidak begitu terkait dengan harga yang diberikan lebih penting bagi peritel untuk meningkatkan persepsi mengenai kualitas. Adapun pula penelitian yang dilakukan oleh Diallo (2012) yang mendukung bahwa perceived risk memediasi hubungan tidak langsung antara store image dan price image terhadap purchase intention. Berdasarkan uraian diatas maka hipotesis keempat pada penelitian ini adalah sebagai berikut:

$\mathrm{H}_{4}$ : a) store image perception; b) store brand price-image berpengaruh terhadap store brand purchase intention melalui perceived risk toward store brands pada salah satu pasar swalayan di Jakarta.

\section{METODE PENELITIAN}

Dalam penelitian ini, peneliti menggunakan tipe penelitian deskriptif dengan pendekatan kuantitatif. Periode yang dipergunakan untuk penelitian ini sendiri dimulai pada Oktober 2017 hingga bulan November 2018. Pada penelitian ini, data yang digunakan adalah data primer dengan metode survei dan menggunakan kuisioner terstruktur untuk mengumpulkan data. Untuk mengukur variabel penelitian, instrumen diadaptasi dari penelitian terdahulu. Skala pengukuran(kecuali profil responden) diukur dengan menggunakan skala likert lima poin dengan 1 menunjukan "sangat tidak setuju", dan 5 menunjukan "sangat setuju". Table 1 menunjukan pengukuran masing-masing variabel dan sumbernya.

Tabel 1

Item Kuisioner

\begin{tabular}{|l|l|l|}
\hline Variabel & Item & \multirow{2}{*}{ Sumber } \\
\cline { 1 - 2 } Store image perception & 9 & \multirow{2}{*}{ Diallo (2012) } \\
\cline { 1 - 2 } Perceived risk toward store brand & 6 & \\
\cline { 1 - 2 } Store brand price image & 6 & \\
\cline { 1 - 2 } Store brand purchase intention & 4 & \\
\hline
\end{tabular}


Kuisioner tersebut kemudian disebarkan kepada responden secara elektronik dengan bantuan google form. Adapun metode pemilihan sampel yang digunakan adalah purposive sampling yaitu dengan memilih warga Indonesia yang sudah berumur diatas 18 tahun. Lebih lanjut, untuk jumlah sampel yang digunakan dalam penelitian ini adalah 206 berdasarkan kriteria (Hair, Sardete, \& Hult, 2014). Berikutnya setelah data dikumpulkan, pendekatan partial least square digunakan untuk menganalisis atau uji model akan dilakukan terhadap data tersebut, yang mana perangkat lunak yang digunakan untuk menganalisis data tersebut adalah Smart PLS 3.

Dari hasil survei kuisoner yang dilakukan didapati karakteristik responden sebagian besar berjenis kelamin wanita yakni sebanyak 56\% dibandingkan pria sebanyak 44\%. Sebelum melakukan analisis model struktural, analisis untuk mengetahui validitas dilakukan untuk memastikan tiap variabel memiliki indikator yang valid. Pada validitas atau loading factor terdapat beberapa indikator yang tidak valid. Dari varabel store image indikator 3,6,8, dan 9. Serta satu indikator dari variabel price image nomor 1 ,memiliki nilai, dan di bawah 0,6 . Sehingga indikator yang tidak valid tersebut dihilangkan dan dilakukan uji faktor loading kembali dan menunjukkan nilai yang di atas 0,6 untuk semua indikator dari tiap-tiap variabel. Dan sudah dapat dikatakan reliabel dikarenakan nilai $A V E$ dan composite reliability diatas 5.

\section{HASIL DAN PEMBAHASAN}

Tabel 2

\section{Hasil Pengujian Hipotesis}

\begin{tabular}{|c|c|c|c|}
\hline & esis & Hasil & t-statistic \\
\hline H1a & SI -INT & ditolak & 0,136 \\
\hline $\mathrm{H} 1 \mathrm{~b}$ & PI-INT & tidak ditolak & 5,611 \\
\hline $\mathrm{H} 2 \mathrm{a}$ & SI-PR & tidak ditolak & 6,931 \\
\hline $\mathrm{H} 2 \mathrm{~b}$ & PI-PR & tidak ditolak & 5,65 \\
\hline $\mathrm{H} 3$ & PR-INT & tidak ditolak & 5,879 \\
\hline $\mathrm{H} 4 \mathrm{a}$ & SI-PR-INT & tidak ditolak & 4,481 \\
\hline $\mathrm{H} 4 \mathrm{~b}$ & PI-PR-INT & tidak ditolak & 4,169 \\
\hline
\end{tabular}

*ket: SI=store image $P I=$ price image, INT=purchase intention, $P R=$ perceived risk

Selanjutnya hasil analisis nilai t-statistic dengan metode bootstrapping yang dilakukan terlampir pada tabel 2. Hipotesis diterima jika nilai $t$-statistic lebih besar dari 1,96. Dari tabel 2 di atas, hasil pengujian H1a sesuai dengan penelitian sebelumnya oleh Diallo (2012) yang menunjukkan store image tidak berpengaruh positif terhadap purchase intention. Berdasarkan penelitian terdahulu menyatakan bahwa citra toko tidak berpengaruh positif karena Dialo data lapangan yang ada tidak mendukung hipotesis penelitian terkait tidak signifikannya hasil yang diperoleh, menyatakan bahwa masyarakat di melihat citra toko hanya sebagai bagian dalam pemilihan brand, bukan untuk meningkatkan niat beli (Diallo, 2012).

Sementara untuk hipotesis H1b tidak ditolak karena nilai t-statistic lebih besar dari 1,96. Lebih lanjut, hasil ini pun sejalan dengan hasil penelitian yang dilakukan oleh Diallo (2012) dan penelitian Sibarani dan Hananto (2015), Menurut Sibarani \& Hananto (2015) price image yang baik dari konsumen, dipengaruhi oleh value yang didapatkan dari produk yang dibeli konsumen. Ketika harga dari sebuah produk store brand sesuai dengan nilai yang ditawarkan, maka konsumen akan beranggapan jka price image dari produk tersebut baik.

Selanjutnya hasil pengujian hipotesis $\mathrm{H} 2$ a menunjukkan hasil yang signifikan. Maka $\mathrm{H}_{2}$ tidak ditolak, yang berarti jika persepsi pelanggan mengenai citra toko meningkat, maka persepsi pelanggan mengenai resiko dalam mengkonsumsi produk store brand akan cenderung berkurang. Berdasarkan data yang diperoleh,hasil menunjukan semakin baik persepsi konsumen pada citra toko maka persepsi mengenai risiko dari mengkonsumsi produk store brand akan menurun. Hasil penelitian ini juga sejalan dengan penelitian yang dilakukan oleh Diallo (2012). 
Selanjutnya, hasil pengujian hipotesis $\mathrm{H} 2 \mathrm{~b}$, tabel 2 menunjukkan hipotesis tidak ditolak dan sejalan dengan hasil penelitian yang dilakukan oleh Diallo (2012), dimana store brand price image berpengaruh negatif terhadap perceived risk toward store brand. Dalam hal ini subjek yang diteliti memposisikan produk store brand miliknya pada tingkat harga premium yang memiliki value yang tinggi. Sehingga harga yang ditetapkan membentuk citra harga yang baik dan berpengaruh negatif terhadap persepsi pelanggan mengenai risiko dari store brand..

Selanjutnya, pada hasil pengujian hipoteis ketiga dinyatakan tidak ditolak. Hasil ini sejalan dengan penelitian yang dilakukan oleh Diallo (2012) yang menyatakan bahwa perceived risk toward store brand berpengaruh negatif terhadap store brand purchase intention. Yang mana berarti, semakin rendah persepsi risiko konsumen terhadap store brand, akan membuat minat beli konsumen semakin tinggi terbukti dalam studi ini.

Setelah itu, hasil pengujian hipotesis H4a menunjukkan hasil yang signifikan sehingga $\mathrm{H} 4 \mathrm{a}$ tidak ditolak. Hasil yang didapat ini sejalan dengan hasil penelitian yang dilakukan Diallo (2012). Dalam penelitian ini, hasil tersebut menunjukkan jika citra toko tersebut meningkat akan membuat niat beli pelanggan meningkat juga namun dengan persepsi akan risiko yang ada dalam benak konsumen yang rendah.

Terakhir hasil pengujian hipotesis H4b berdasarkan tabel 2 menunjukkan hasil yang signifikan dan menyatakn $\mathrm{H} 4 \mathrm{~b}$ tidak ditolak. Hasil yang didapat pada penelitian ini sejalan dengan hasil penelitian yang dilakukan Diallo (2012). Menurut Lambert, dalam Wu, dkk (2011) persepsi pelanggan mengenai risiko dapat mempengaruhi persepsi pelanggan mengenai harga produk, di mana konsumen menganggap produk dengan harga yang mahal memiliki kualitas yang baik. Sehingga harga yang ditawarkan harus sesui dengan value yang didapat oleh konsumen yang membeli produk store brand agar pelanggan tidak merasa dirugikan dengan memilih produk store brand.

\section{KESIMPULAN DAN SARAN}

Penelitian yang mengacu kepada jurnal Diallo (2012) menunjukkan hasil yang sejalan dimana hanya pengaruh secara langsung store image terhadap purchase intention yang ditolak dan menunjukkan hasil yang tidak signifikan. Dan juga hasil penelitian ini memberikan saran bagi perusahaan untuk dapat menurunkan persepsi negatif konsumen mengenai produk store brand, dengan kegiatan pemasaran tentang value yang didapat dari membeli produk store brand yang berkualitas baik dan dengan harga yang bersahabat serta memiliki varian produk yang banyak.

\section{DAFTAR PUSTAKA}

Bao, Y., Yeqing, B., \& Shibin, S. (2010). Motivating purchase of private brands: effects of store image, product signatureness, and quality variation. Journal Business Reseach, 220-226.

Bauer, R. (1960). Consumer behavior at risk taking. In : Cox,D.F.(Ed.), Risk Taking and Information Handling in Consumer Behavior. Harvard University Press, Boston, 2233.

Bloemer, \& Shroder. (2002). Lingking Perceive Service Quality and Service Loyalty: A Multidimensional Perspective. European Journal of Marketing.

Diallo, M. F. (2012). Effects of store image and store brand price-image on store brand purchase intention: application to an emerging market. journal of retailing and consumer service, 360-367.

Diallo, M. F., Chandon, J.-L., Cliquet, G., \& Philippe, J. (2013). Factors influencing consumer behaviour toward store brands: evidence from the French Market. International Journal of Retail \& Distribution Management Vol.41 No.6. 
Dursun, I., Ebru, K., \& Sezen, B. (2012). store brand purchase intention: effect of risk, quality, familiarity and store brand shelf space. Procedia social and behavioral science 24, 1190-1200.

Febrianto, H. (2015, januari 9). Sindonews.com. Diambil kembali dari Sindonews.com: https://ekbis.sindonews.com/read/948463/34/carrefour-akan-berubah-nama-jaditransmart-1420802022

Forbes. (2011, 6 29). Forbes.com. Diambil kembali dari forbes.com: https://www.forbes.com/sites/lauraheller/2011/06/29/10-secrets-about-storebrands/\#4b445d707db0

Hair, J., Sardete, M., \& Hult, G. (2014). A Primer on partial least square structural equation model (PLS-SEM). London: SAGE Publication Inc.

Hamilton, R. P. (2008). price image in retail management. dissertation, 10.

Knox, B. (2000). Consumer perception and understanding of risk from food. British Medical Bulletin, 97-109.

Kotler, P., \& Keller, K. L. (2009). Manajemen Pemasaran edisi 9. Jakarta: Erlangga.

Lake, L. (2016, September 24). What is Perceived Risk and How Can We Overcome it with Our Messaging? Dipetik November 10, 2016, dari www.thebalance.com: https://www.thebalance.com/what-is-perceived-risk-2295541

Paul C, S., Yeh, G. Y.-Y., \& Hsiao, C.-R. (2011). The effect of store image and service quality on brand image and purchase intention for private label brands. Australasian Marketing Journal, 30-39.

Schiffman, \& Kanuk. (2008). Perilaku konsumen Edisi 7. Jakarta: Indeks.

Schiffman, L. G., \& Kanuk, L. L. (2010). Customer Behavior. New Jersey: Prentice Hall.

Selvaraj, U. (2015). A Study on Consumer Perception Towards. Indian journal of research, 382.

Shah, H., Aziz, A., Jaffari, A., Waris, S., Ejaz, W., Fatimah, W., \& Shaerezi, K. (2012). The Impact of Brands on Consumer Purchase Intentions. Asian Journal of Business Management 4(2), 105-110.

Sibarani, M., \& Hananto, A. (2015). Analisis Pengaruh Store Image, Store Brand Price Image dan Store Brand Perceived Risk sebagai variabel mediasi terhadap Purchase Intention pada Produk Store Brand Ritel Watsons. Departemen Manajemen, Fakultas Ekonomi, Universitas Indonesia.

Suryana, P. (2013). Analisis Faktor Yang Mempengaruhi Keputusan Pembelian dan Implikasinya pada Minat Beli Ulang. Jurnal Trikonomika Vol 12 No 2, 190-200.

Utami, C. W. (2010). Manajemen Ritel: Strategi dan Implementasi Operasional Bisnis Ritel Modern di Indonesia. Jakarta: Salemba Empat.

Zielke, S. (2010). How price-image dimension influence shopping interactions for different store formats? European Journal of Marketing 44 (6), 748-770. 
